\title{
Video Article \\ Generation of Prostate Cancer Cell Models of Resistance to the Anti-mitotic Agent Docetaxel
}

\author{
Lisa Mohr ${ }^{1}$, Marc Carceles-Cordon ${ }^{1}$, Jungreem Woo ${ }^{1}$, Carlos Cordon-Cardo ${ }^{1}$, Josep Domingo-Domenech ${ }^{1}$, Veronica Rodriguez-Bravo ${ }^{1,2}$ \\ ${ }^{1}$ Department of Pathology, Tisch Cancer Institute, Icahn School of Medicine at Mount Sinai \\ ${ }^{2}$ Department of Oncological Sciences, Tisch Cancer Institute, Icahn School of Medicine at Mount Sinai
}

Correspondence to: Veronica Rodriguez-Bravo at veronica.rodriguez-bravo@mssm.edu

URL: https://www.jove.com/video/56327

DOI: doi: $10.3791 / 56327$

Keywords: Cancer Research, Issue 127, Prostate Cancer (PC), Chemotherapy Resistance, Anti-mitotic Agents, Taxanes, Docetaxel, Microtubule Targeting Agents

Date Published: 9/8/2017

Citation: Mohr, L., Carceles-Cordon, M., Woo, J., Cordon-Cardo, C., Domingo-Domenech, J., Rodriguez-Bravo, V. Generation of Prostate Cancer Cell Models of Resistance to the Anti-mitotic Agent Docetaxel. J. Vis. Exp. (127), e56327, doi:10.3791/56327 (2017).

\section{Abstract}

Microtubule targeting agents (MTAs) are a mainstay in the treatment of a wide range of tumors. However, acquired resistance to chemotherapeutic drugs is a common mechanism of disease progression and a prognostic-determinant feature of malignant tumors. In prostate cancer (PC), resistance to MTAs such as the taxane Docetaxel dictates treatment failure as well as progression towards lethal stages of disease that are defined by a poor prognosis and high mortality rates. Though studied for decades, the array of mechanisms contributing to acquired resistance are not completely understood, and thus pose a significant limitation to the development of new therapeutic strategies that could benefit patients in these advanced stages of disease. In this protocol, we describe the generation of Docetaxel-resistant prostate cancer cell lines that mimic lethal features of late-stage prostate cancer, and therefore can be used to study the mechanisms by which acquired chemoresistance arises. Despite potential limitations intrinsic to a cell based model, such as the loss of resistance properties over time, the Docetaxel-resistant cell lines produced by this method have been successfully used in recent studies and offer the opportunity to advance our molecular understanding of acquired chemoresistance in lethal prostate cancer.

\section{Video Link}

The video component of this article can be found at https://www.jove.com/video/56327/

\section{Introduction}

An increased rate of proliferation caused by the loss of cell cycle control is a hallmark of cancer ${ }^{1}$. This functional property renders cancer cells uniquely dependent on the fidelity of the cell cycle's key processes during S- and M-phases, which has led to the development of various cell cycle perturbing drugs that induce DNA damage or mitotic defects. Although numerous anti-mitotic agents, like inhibitors of mitotic kinases or motor proteins, are currently being developed and tested in clinical trials, legacy microtubule targeting agents (MTAs) continue to be the only clinically approved approach for targeting mitosis in cancer, ${ }^{2,3,4}$. MTAs either destabilize (Vinblastine, Vincristine, Vinorelbine) or stabilize (taxanederived agents Paclitaxel, Docetaxel or Cabazitaxel) microtubules and thereby prevent the formation of a functioning mitotic spindle ${ }^{5,6}$. These agents trigger the spindle assembly checkpoint ${ }^{7,8}$, which results in a prolonged mitotic arrest and eventual cell death in cultured cells ${ }^{9,10}$ and mitotic defects in tumors ${ }^{11,12}$ and are therefore useful for treating a large variety of cancers, among them prostate cancer ${ }^{13}$.

Prostate cancer is the most frequently diagnosed cancer and a leading cause of cancer related deaths in men ${ }^{14}$. Antimitotic agents such as Docetaxel improve prostate cancer patient's survival and are a mainstay in the treatment of this disease ${ }^{15,16,17}$. Unfortunately, despite initial tumor shrinkage, tumor cells often develop drug resistance during treatment. Several cellular mechanisms have been implicated in causing the development of chemoresistance, including deregulation of apoptotic and inflammatory pathways, or activation/overexpression of drug efflux pumps like the ATP-binding cassette transporter P-glycoprotein (P-gp/ABCB1), the latter of which results in the export of chemotherapeutic agents out of the cells ${ }^{18,19}$. Resistance to taxanes has also been linked with other causes, such as changes in the expression of tubulin isotypes or tubulin mutations, which prevent interaction between the drug and its target ${ }^{20,21}$. Furthermore, resistance has been related to genome instability accumulation and tumor heterogeneity ${ }^{22,23}$. However, the mechanisms contributing to taxane resistance are not completely understood, which is evident by the absence of therapeutic strategies that prevent its appearance. Therefore, there is an urgent need to generate experimental models that assist in the dissection of these mechanisms and to identify novel therapeutic approaches that prevent the development of resistance to these drugs.

In this article we describe a method which allows the generation of Docetaxel-resistant (DR) prostate cancer cells. We will further describe how to validate the resistance status of these cells using colony formation assays and quantitative RT-PCR. Cells produced by this method have the advantage of recapitulating many of the molecular features found in publicly available human tumor sample databases with the added benefit of providing the versatility to perform a wide variety of experimental assays over longer periods of time than permitted by tumor samples. These cancer models of therapy resistance can be expanded for many weeks in tissue culture, and among other approaches, can be genetically manipulated, visualized by microscopy methods and analyzed for gene expression. Furthermore, they can be xenotrasplanted 
in mice to further analyze effects in tumor formation and growth in vivo. Currently, the main alternative method to study drug resistance in the context of prostate cancer is the direct analysis of tumor samples. While these samples present a very potent system to gather information about gene expression and mutational status of the given tumors, access to them can be very limited and they are difficult to maintain for further manipulations and experimental analysis, which can easily be done with the cell lines generated with this protocol ${ }^{24,25}$. Importantly, in the future, alternative approaches such as the generation of human derived organoids directly from patients would be a very powerful tool and alternative to the present method ${ }^{26,27}$. Since they will recapitulate in a 3D context what a tumor was in its original environment, organoids will be the perfect model between cell lines and human tumors. Yet, the experimental cell models described in this protocol are still more affordable to maintain and suitable for faster analysis. The results obtained by studying these cell lines can be extrapolated to and corroborated in human samples and 3D cultures. Therefore, this protocol may be of interest for researchers seeking cell models to study chemoresistance mechanisms in any cell line, since our protocol can be adapted to the study of other drugs and cancer types. The methods described here are easy to apply in any laboratory, affordable and allow preliminary studies of the molecular and cellular mechanisms of drug resistance.

Protocol

\section{Determination of the Docetaxel Concentration Causing $50 \%$ Decrease in Colony Formation Ability (IC50)}

NOTE: In this protocol, Docetaxel IC50 concentration has been evaluated using colony formation ability. Alternative methods used to evaluate cell viability (i.e., MTS assays) can be used based on investigators' preferences.

1. Grow DU145 or $22 R v 1$ cells in a $75 \mathrm{~cm}^{2}$ flask and prepare enough stock of $10 \mathrm{mM}$ Docetaxel diluted in DMSO to be used in future experiments.

2. To plate cells for determination of IC50 of Docetaxel, remove media from the flask, carefully wash cells with $5 \mathrm{~mL}$ PBS, and incubate with 2 $\mathrm{mL} 0.05 \%$ Trypsin-EDTA for $3-5 \mathrm{~min}$ at $37^{\circ} \mathrm{C}$ to detach cells from the flask surface.

3. Rinse trypsinized cells from the flask using $5 \mathrm{~mL}$ of fresh media and collect the cell suspension in a $15 \mathrm{~mL}$ tube. Pellet cells by centrifugation ( 300 x g, 3 min, room temperature (RT)).

4. Remove the supernatant, resuspend the cell pellet in $5 \mathrm{~mL}$ of fresh media and count the cells. Dilute the cell suspension to $2-2.5 \times 10^{5}$ cells/ $\mathrm{mL}$ for DU145 and $4-4.5 \times 10^{5}$ cells $/ \mathrm{mL}$ for $22 \mathrm{Rv} 1$, mix well by pipetting up and down and seed $2 \mathrm{~mL}$ of the suspension in each well of two 6 well plates.

5. After $24 \mathrm{~h}$, when the cells are at $70-80 \%$ confluence, add dose-escalating Docetaxel concentrations of $1 \mathrm{nM}, 2.5 \mathrm{nM}, 5 \mathrm{nM}, 10 \mathrm{nM}, 25 \mathrm{nM}, 50$ $\mathrm{nM}, 100 \mathrm{nM}, 250 \mathrm{nM}, 500 \mathrm{nM}$, and $1000 \mathrm{nM}$ to each well. Treat the control well with DMSO at the highest volume used for Docetaxel (Figure 2A).

6. After $72 \mathrm{~h}$, aspirate drug containing media and add $2 \mathrm{~mL}$ of fresh media. Within approximately $4-5$ days, the plates will be ready for staining

7. To stain the colonies, wash them gently with $2-3 \mathrm{~mL}$ PBS and incubate them with $2-3 \mathrm{~mL}$ crystal violet solution $(0.1 \%$ w/v in $10 \%$ formalin) for $20 \mathrm{~min}$ inside the tissue culture hood or a fume hood.

8. Remove staining solution and wash plates with $2-3 \mathrm{~mL}$ of $\mathrm{H}_{2} \mathrm{O}$, remove $\mathrm{H}_{2} \mathrm{O}$ and air-dry plates.

9. Analyze the results by visualizing the wells to determine which one has the Docetaxel concentration that decreases cell viability by $50 \%$ (IC50). Manually count colonies with the help of a marker pen (to avoid counting the same colonies twice) and represent the percentage of cell viability in a graph (Figure 2A). Finally, take digital images of the plates for figure representation (as shown in Figure 3A).

\section{Generation of Docetaxel-resistant Prostate Cancer Cells}

NOTE: Perform cell treatments using the same Docetaxel solution stock used for determination of IC50 drug concentration (prepare enough stock in advance for experimental use). Always keep a small flask of cells from the previous step, just in case something does not work well. Parental cells should be grown in parallel in a small flask throughout the whole procedure and exposed to vehicle (DMSO) in corresponding volumes mimicking the amounts used in the Docetaxel treated flasks.

1. Plate DU145 or $22 R v 1$ cells in $150 \mathrm{~cm}^{2}$ flasks containing $20 \mathrm{~mL}$ of media $\left(3.5 \times 10^{6}\right.$ cells per flask for DU145 and $6.5^{\star} 10^{6}$ cells per flask for 22Rv1). Use of 10 to 20 flasks of cells is recommended to have enough cells at the end of the protocol.

2. After $24 \mathrm{~h}$, when cells are at about $70-80 \%$ confluence (Figure 2B, before Docetaxel), add Docetaxel at the IC50 concentration determined in step 1 of the protocol ( $5 \mathrm{nM}$ for the cells described in this protocol).

3. After $72 \mathrm{~h}$, aspirate drug containing media and add fresh, Docetaxel-free media (Figure $2 \mathrm{~B}, 72 \mathrm{~h}$ after Docetaxel). Change the media every 3-4 days. Within approximately 1-2 weeks, resistant clones will appear evident under the microscope (Figure 2B, 7 and 14 days after Docetaxel).

4. Aspirate media, carefully wash cells with $15 \mathrm{~mL}$ PBS and incubate with $4 \mathrm{~mL} 0.05 \%$ Trypsin-EDTA for $3-5$ min at $37^{\circ} \mathrm{C}$ to detach cells from the flask surface.

5. Resuspend trypsinized cells from the flask using $8 \mathrm{~mL}$ of fresh media. Pool cells from all treated flasks. Pellet cells by centrifugation ( $300 \mathrm{xg}$, 3 min, RT).

6. Remove the supernatant, resuspend the cell pellet in $20 \mathrm{~mL}$ of fresh media and plate the cells in $150 \mathrm{~cm}^{2}$ flasks $\left(3.5 \times 10^{6}\right.$ cells per flask for DU145 and $6.5^{*} 10^{6}$ cells per flask for 22Rv1).

7. After $24 \mathrm{~h}$, when cells are at about $70-80 \%$ confluence, add $5 \mathrm{nM}$ Docetaxel (initial IC50 concentration) again.

8. Repeat steps 2.3 to 2.6 on day 3 .

9. After $24 \mathrm{~h}$, when cells are at about $70-80 \%$ confluence, treat cells with 2 X IC50 Docetaxel concentration (10 nM for the cells described in this protocol). 
10. Repeat steps 2.3 to 2.8 , following a dose-escalation of Docetaxel concentrations ( $25 \mathrm{nM}, 50 \mathrm{nM}, 100 \mathrm{nM}$ and $250 \mathrm{nM})$, to generate a stable population of cells growing in your flasks under the final highest concentration. For higher concentrations, the dose-escalation protocol can be implemented for up to 6 months until the $1,000 \mathrm{nM}$ concentration is reached (Figure 1A).

\section{Functional Characterization of Acquired Docetaxel Resistance by Colony Formation Assay}

NOTE: In this protocol, chemoresistance has been evaluated using colony formation assays. Alternative methods used to evaluate cell viability

(i.e., MTS assays) can be used based on investigators' preferences.

1. Plate 2,000 cells (DU145 or 22Rv1, both parental and Docetaxel-resistant) per well in 6-well plates, using $2 \mathrm{~mL}$ of media per well.

2. After $24 \mathrm{~h}$, add increasing concentrations of Docetaxel (parental cells: 0.25, 0.5, 1, 2.5 and $5 \mathrm{nM}$; DR cells: 50, 125, 250, 500 and 1,000 nM). For both DU145 and 22Rv1 cell lines. Add DMSO only to one well as a control at the same volume used for the highest Docetaxel dose.

3. After $72 \mathrm{~h}$, aspirate drug containing media and add fresh Docetaxel-free media.

4. Incubate plates for 1-2 weeks until colonies are visible under the microscope.

5. To stain the colonies, wash them gently with $2-3 \mathrm{~mL}$ PBS and incubate them with $2-3 \mathrm{~mL}$ crystal violet solution $(0.1 \% \mathrm{w} / \mathrm{v}$ in $10 \%$ formalin) for 20 min inside the tissue culture hood or a fume hood.

6. Remove staining solution and wash plates with $2-3 \mathrm{~mL}$ of $\mathrm{H}_{2} \mathrm{O}$, remove $\mathrm{H}_{2} \mathrm{O}$ and air-dry plates.

7. Analyze result by visualizing the wells and manually counting colonies with the help of a marker pen (to avoid counting the same colonies twice) and represent the percentage of cell viability in a graph. Take digital images of the plates for figure representation (Figure 3A).

\section{Phenotypic Characterization of Docetaxel Resistance Acquired Phenotype via qRT-PCR Analysis}

NOTE: Docetaxel-resistant (DR) cells exhibit a different expression profile compared to their parental cell lines ${ }^{28,29}$. Therefore, the success of the selection can be verified by qRT-PCR using primers for specific markers (for primer sequences, refer to the materials section; for details, refer to the results section). This should be done after each round of selection starting after the third round. Alternatively, evaluation of Docetaxelresistant phenotype by Western blotting is also possible.

1. Extract RNA from both parental and Docetaxel-resistant cells using an RNA extraction kit and following the manufacturer's instructions (see the Table of Materials and reagents for details). Using a minimum of $1-2 \times 10^{6}$ cells is recommended.

2. Quantify RNA at $260 \mathrm{~nm}$ absorbance, using a spectrophotometer. For best purity, the $260 \mathrm{~nm} / 280 \mathrm{~nm}$ absorbance ratios should be close to 2.0 .

3. Perform reverse transcription to obtain complementary DNA (cDNA) using the reverse transcription kit and following the manufacturer's instructions (see the Table of Materials and reagents for details), using $1 \mu \mathrm{g}$ of RNA in a $20 \mu \mathrm{L}$ reaction mix (if a higher amount of cDNA is needed, scale up the reaction mix accordingly).

4. Prepare the qPCR reaction in triplicate for each gene of interest as follows:

- $2 \mu \mathrm{L}$ of $10 \mu \mathrm{M}$ forward primer

- $2 \mu \mathrm{L}$ of $10 \mu \mathrm{M}$ reverse primer

- $10 \mu \mathrm{L}$ SYBR Green PCR master mix

$-5 \mu \mathrm{L} \mathrm{H}_{2} \mathrm{O}$

- $1 \mu \mathrm{L}$ of the newly prepared cDNA from step 4.3.

NOTE: See Table of Materials for the sequences of primers used in this protocol.

5. Set the PCR program as follows:

$-95^{\circ} \mathrm{C}$ for $15 \mathrm{~min}$

$-94^{\circ} \mathrm{C}$ for $30 \mathrm{~s}$

$-56{ }^{\circ} \mathrm{C}$ for $40 \mathrm{~s}$

$-72{ }^{\circ} \mathrm{C}$ for $30 \mathrm{~s}$

6. To analyze qPCR results and determine changes in gene expression between parental and DR samples, the cycle threshold (Ct) values for each gene of interest are determined in triplicate and the average normalized to the loading control (Actin triplicate average) for DR (Ct $\mathrm{DR}$ ) and parental cells (Ct parental). Values for the parental cells are normalized to 1. $\triangle \mathrm{Ct}$ (Ct DR - Ct parental) is determined to obtain final mRNA fold changes and represented in a graph. An increase of $>2$ or a decrease of $<0.5$ are considered significant and a good validation of the establishment of the Docetaxel acquired resistant phenotype (Figure 3B).

\section{Representative Results}

This protocol will lead to the generation of Docetaxel-resistant (DR) prostate cancer cells. The timeline for completion may range from 4 to 7 months as summarized in the schematic representation of the protocol steps in Figure 1A and Figure 1B. The time investment could differ depending on the cell line of choice and the range of drug concentrations used as described in the protocol. Importantly, the determination of the Docetaxel IC50 concentration for each cell line allows the design of the drug escalating concentration range to use in the protocol for the cells of choice (Figure 2A). Once the protocol is started, initial Docetaxel effects on DU145 and 22Rv1 cells can be observed at different time points under the microscope to monitor if the protocol is working properly. Suggested time points to monitor the Docetaxel treatment process are: before Docetaxel exposure (baseline), after Docetaxel exposure for $72 \mathrm{~h}, 7$ days and 14 days. Note that only a minority of tumor cells survive the Docetaxel exposure and generate clones, which can be observed under the microscope (Figure 2B). 
Representative colony formation assays and quantification graphs of parental and the newly generated Docetaxel-resistant (DR) cells are shown in Figure 3A. Note that the generated Docetaxel-resistant cells can survive drug concentrations up to 1,000-fold higher than the parental cells.

Finally, the Docetaxel-resistant phenotype can be validated by qRT-PCR (Figure 3B). Note that Docetaxel-resistant cells, compared to the parental cells, display characteristic up-regulation of ABCB1 and GATA2 and down-regulation of CK19 and CDH1. These genes were selected for validation because we have already experimentally shown in our previously published work GATA2 upregulation and downregulation of CK19 together with $\mathrm{CDH} 1$ in both DR cell models ${ }^{28,29}$. The ABCB1 gene was also selected as a staple gene that has been shown by others to be consistently upregulated in drug resistant cells ${ }^{18,19}$. However, it is important to note that other genes may be chosen according to literature and depending on the cell models and the drugs chosen for generating resistant cells by the researcher.

A Timeline for the Generation of Docetaxel-resistant Prostate Cancer Cell Models

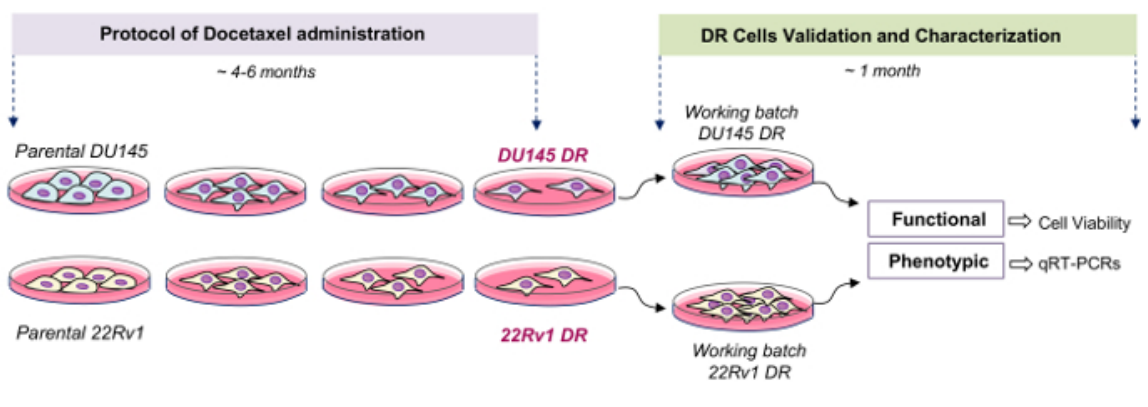

B

$$
\text { Cell Viability to Docetaxel }
$$

qRT-PCRs
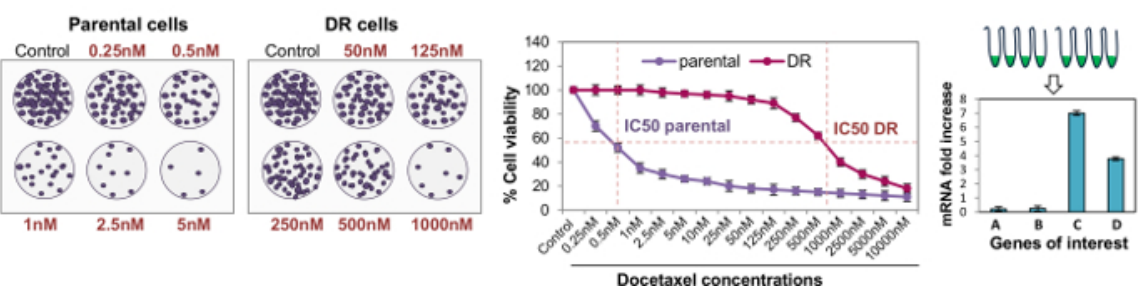

Figure 1: Timeline for the generation of Docetaxel-resistant prostate cancer cell models. (A) Representative diagram of the protocol timeline for generation of Docetaxel-resistant cell models. Illustration depicts the Docetaxel treatment, validation steps, and time needed for each part. (B) Schematic representation of the validation steps of the protocol including functional colony formation assays of parental and Docetaxelresistant cells treated with the indicated Docetaxel concentrations for $72 \mathrm{~h}$ (in red), representative graph of colony percentage and qRT-PCR for phenotypic validation. Please click here to view a larger version of this figure. 
A
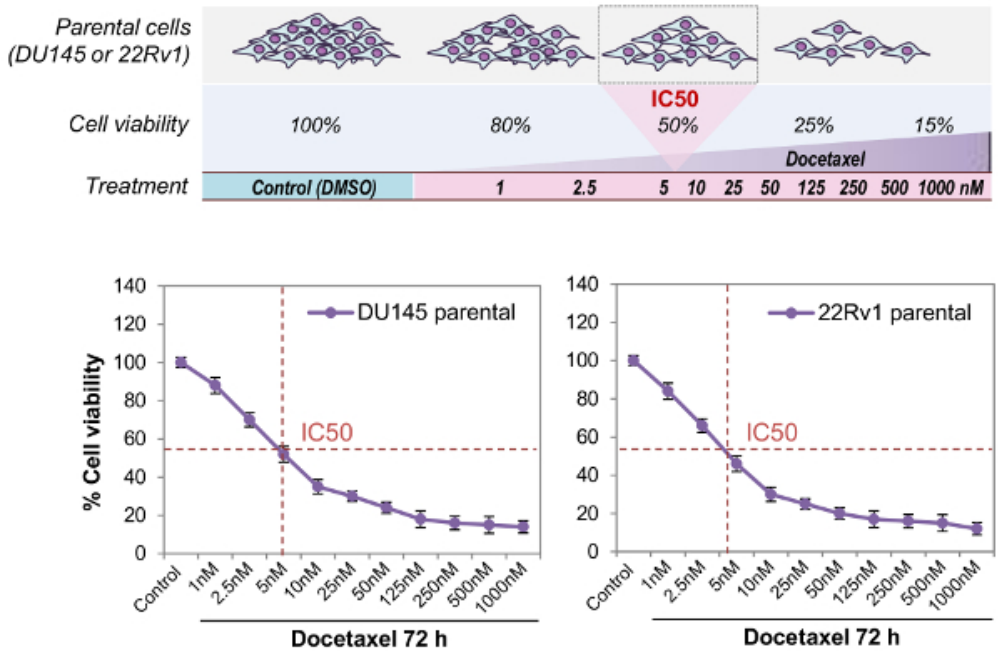

B
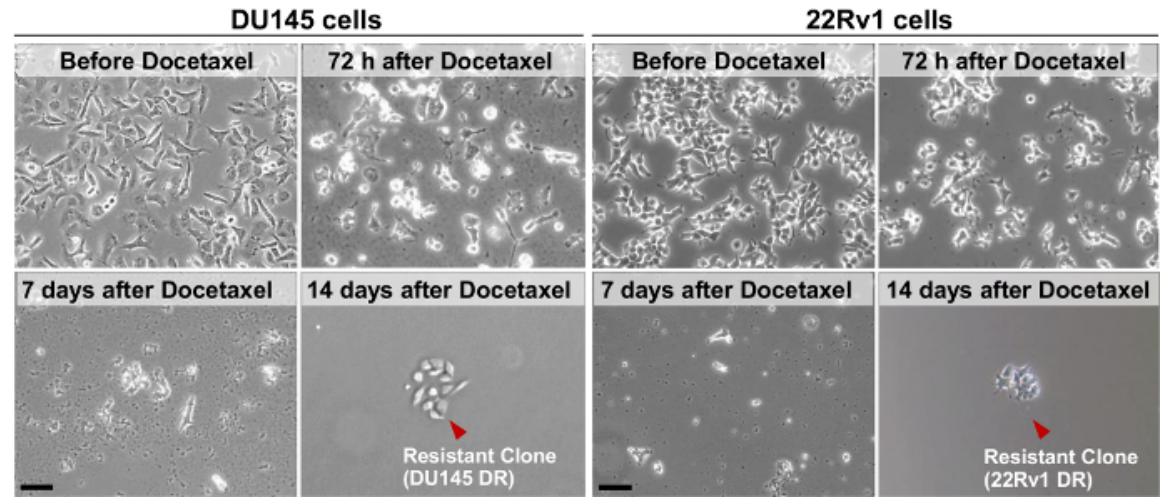

Figure 2: Generation of Docetaxel-resistant prostate cancer cell model systems. (A) Diagram depicting the determination of the Docetaxel IC50 in the parental prostate cancer cell lines DU145 and 22Rv1 (Step 1 of the protocol). Expected percentages of cell viability and the Docetaxel dose-escalating concentrations needed are included. Representative DU145 and $22 \mathrm{Rv} 1$ cell viability graphs indicating $5 \mathrm{nM}$ as the IC50 after $72 \mathrm{~h}$ of Docetaxel exposure are included. The experiments are triplicates and data represents the mean \pm SD. (B) Representative bright field microscopy images of DU145 and 22Rv1 cells at indicated times during the generation of Docetaxel resistance (Step 2 of the protocol). Red arrows indicate a Docetaxel resistant clone after the protocol is completed. Scale bars $=50 \mathrm{~nm}$. Please click here to view a larger version of this figure. 
A
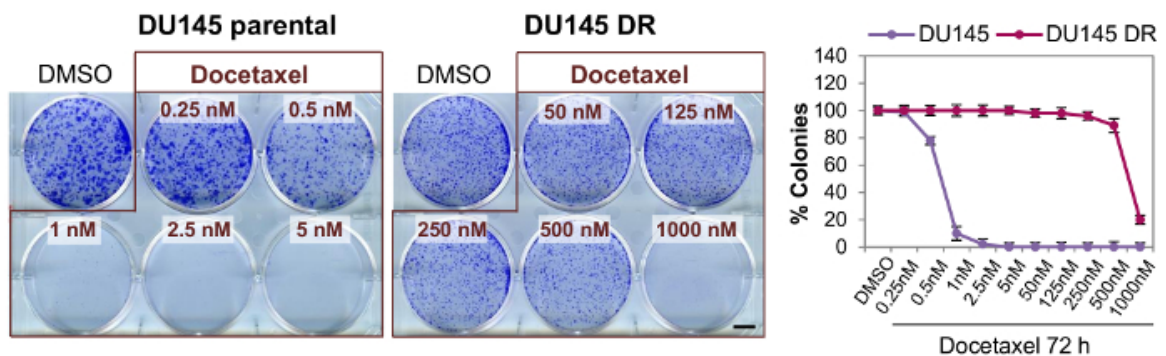

22Rv1 parental

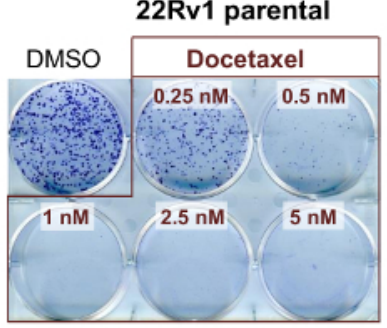

22Rv1 DR

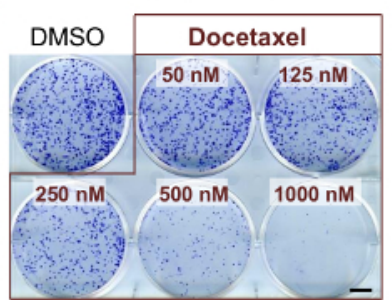

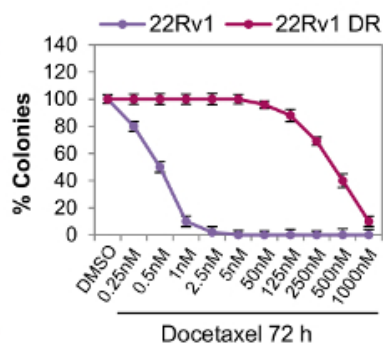

B

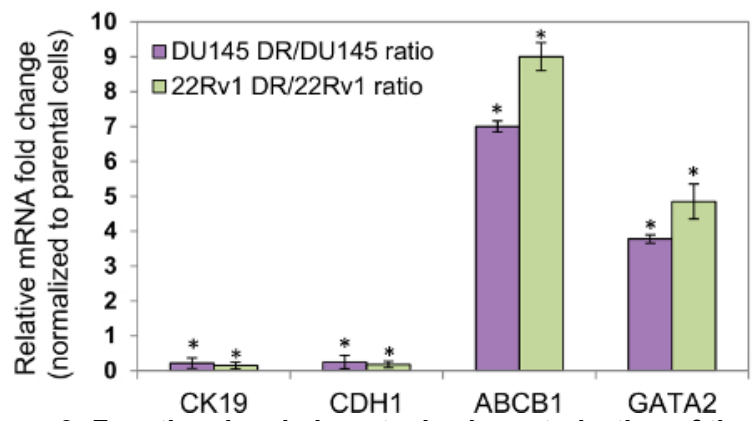

Figure 3: Functional and phenotypic characterization of the Docetaxel-resistant cell models. (A) Representative colony formation assays of parental and Docetaxel-resistant cells treated with the indicated Docetaxel concentrations for $72 \mathrm{~h}$. Percentage of colonies for every treatment concentration is represented in the included graph. The experiments are triplicates and data represents the mean \pm SD. Scale bars $=5 \mathrm{~mm}$. (B) DR/parental relative mRNA fold increase quantified by qRT-PCR of ABCB1, GATA2, CK19 and CDH1 are shown. All qPCR raw data is normalized to Actin (see protocol for details). The experiments are triplicates and data represent the mean \pm SD. ${ }^{*} p<0.05$. Please click here to view a larger version of this figure.

\section{Discussion}

In this manuscript, we describe a method to generate Docetaxel-resistant prostate cancer cell model systems that allows for the study of mechanisms contributing to acquisition of the chemoresistance phenotype. While this approach is highly reliable and reproducible, some potential limitations should be considered. Since only a small fraction of the bulk population of cells will exhibit chemoresistance ${ }^{28}$, it is recommended to start with a large population of cells (we usually plate 20 flasks of $150 \mathrm{~cm}^{2}$, which account for approximately $1.2 \times 10^{8}$ cells). Key steps of the protocol should be considered to ensure success of the procedure. First, it is very important to use the same Docetaxel freshly prepared stock for long term usage $\left(10 \mathrm{mM}\right.$ stock aliquots can be used for years when stored properly in at $\left.-80^{\circ} \mathrm{C}\right)$. Slight changes in the Docetaxel aliquot can impact the results of IC50, generation of the cell line timing and the colony formation results. Second, it is crucial to start the protocol determining the IC50 in each individual cell line, since variations can occur when using a new batch of cells. Third, it is essential to monitor that the drug treatment is effective by checking cells under the microscope frequently so any errors can be detected quickly and corrected. Finally, we recommend to always keep a stock of intermediate steps in case of contamination or unexpected problems that could affect the viability of the cells in the middle of the protocol. Importantly, our protocol aims to generate models of drug resistance by exposing prostate cancer cells to high doses of Docetaxel for $72 \mathrm{~h}$ followed by long recovery periods, rather than lower constant concentrations of the drug in an attempt to mimic the best clinical scenario reported for prostate cancer treatment with this taxane agent ${ }^{15,16}$.

Additionally, it should be noted that drug-resistant cells exhibit a high plasticity, which may lead to a progressive loss of acquired resistance properties over time. Therefore, extending the use of these cells for more than 2-3 months in culture is not recommended. If a permanent supply is needed it is advisable to continuously generate new batches of resistant cells. However, if batches of cells have been cultured for an extended time, colony formation assays and qPCR can be used to reevaluate their resistance. Another alternative is to boost waning resistance by treating 
the cells with a high dose of Docetaxel for $72 \mathrm{~h}(500-1,000 \mathrm{nM})$. After a recovery period of one to two weeks, the phenotype can be re-tested by qPCR and colony formation assays. It is also possible, although not recommended, to store aliquots of treated cells in liquid nitrogen (in FBS, $10 \%$ DMSO). Please note that after a freeze-thaw cycle, the chemoresistance phenotype should always be re-evaluated with the aforementioned methods.

Despite these caveats, $\mathrm{e}^{28,29}$ and others ${ }^{30,31,32,33}$ were able to successfully employ these model systems to identify key novel cellular and molecular mechanisms leading to elevated tumor-initiating capacity, cell survival, and aggressiveness in Docetaxel-resistant cells. Using these cancer cell model systems, we discovered that cells exhibiting an undifferentiated phenotype, characterized by the absence of epithelial and prostate-related differentiation markers and overexpression of targetable developmental (Notch and Hedgehog) signaling pathways, survive chemotherapeutic exposure ${ }^{28}$. In a second study, using these models together with publicly available patient gene data sets ${ }^{24,25}$, we uncovered that the pioneer transcription factor GATA2 is highly overexpressed in metastatic castration-resistant chemotherapy-resistant prostate cancer cells. GATA2 increases the survival of cells by directly activating an IGF2-dependent downstream kinase signaling network ${ }^{29}$. Notably, these studies helped to identify novel key roles of GATA2 in advanced metastatic prostate cancer aggressiveness ${ }^{34}$.

The development of drug resistance is a problem that is not limited to Docetaxel and prostate cancer, as it is prevalent among many other types of cancers treated with a wide array of chemotherapeutic drugs. Indeed, similar restrictions on the availability of experimental models apply, and it is conceivable that our protocol can be adapted to study other cancer types and their respective chemoresistance mechanisms.

The generation of Docetaxel-resistant cells as described in this protocol can be used as a functional tool to identify novel relevant molecular and cellular mechanisms of chemoresistance. This opens the door to finding new targets, upon which the development of new treatments for highly malignant prostate cancer might articulate, pushing once more the boundaries of what we know about this disease and how we treat its patients.

\section{Disclosures}

The authors declare that they have no competing financial interests.

\section{Acknowledgements}

V.R.-B. receives funding from the U.S. Department of Health \& Human Services, NIH, National Cancer Institute grant number 1 K22 CA207458-01 and J.D.-D. receives funding from U.S. Department of Health \& Human Services, NIH, National Cancer Institute grant number 1 R01 CA207311-01.

\section{References}

1. Hanahan, D., \& Weinberg, R. A. Hallmarks of cancer: the next generation. Cell. 144 (5), 646-674 (2011).

2. Lapenna, S., \& Giordano, A. Cell cycle kinases as therapeutic targets for cancer. Nature reviews. Drug discovery. 8 (7), $547-566$ (2009).

3. Jackson, J. R., Patrick, D. R., Dar, M. M., \& Huang, P. S. Targeted anti-mitotic therapies: can we improve on tubulin agents? Nature reviews. Cancer. 7 (2), 107-117 (2007).

4. Dumontet, C., \& Jordan, M. A. Microtubule-binding agents: a dynamic field of cancer therapeutics. Nature reviews. Drug discovery. 9 (10), 790-803 (2010).

5. Schiff, P. B., Fant, J., \& Horwitz, S. B. Promotion of microtubule assembly in vitro by taxol. Nature. 277 (5698), 665-667 (1979).

6. Schiff, P. B., \& Horwitz, S. B. Taxol stabilizes microtubules in mouse fibroblast cells. Proceedings of the National Academy of Sciences of the United States of America. 77 (3), 1561-1565 (1980).

7. Musacchio, A., \& Salmon, E. D. The spindle-assembly checkpoint in space and time. Nature reviews. Molecular cell biology. 8 (5), $379-393$ (2007).

8. Kops, G. J. P. L., Weaver, B. A. A., \& Cleveland, D. W. On the road to cancer: aneuploidy and the mitotic checkpoint. Nature reviews. Cancer. 5 (10), 773-785 (2005).

9. Derry, W. B., Wilson, L., \& Jordan, M. A. Substoichiometric binding of taxol suppresses microtubule dynamics. Biochemistry. $\mathbf{3 4}$ (7), 2203-2211 (1995).

10. Jordan, M. A., Wendell, K., Gardiner, S., Derry, W. B., Copp, H., \& Wilson, L. Mitotic block induced in HeLa cells by low concentrations of paclitaxel (Taxol) results in abnormal mitotic exit and apoptotic cell death. Cancer research. 56 (4), 816-825 (1996).

11. Orth, J. D., Kohler, R. H., Foijer, F., Sorger, P. K., Weissleder, R., \& Mitchison, T. J. Analysis of mitosis and antimitotic drug responses in tumors by in vivo microscopy and single-cell pharmacodynamics. Cancer research. 71 (13), 4608-4616 (2011).

12. Zasadil, L. M., et al. Cytotoxicity of paclitaxel in breast cancer is due to chromosome missegregation on multipolar spindles. Science translational medicine. 6 (229), 229 ra43 (2014).

13. Dominguez-Brauer, C., Thu, K. L., Mason, J. M., Blaser, H., Bray, M. R., \& Mak, T. W. Targeting Mitosis in Cancer: Emerging Strategies. Molecular cell. 60 (4), 524-536 (2015).

14. Torre, L. A., Bray, F., Siegel, R. L., Ferlay, J., Lortet-Tieulent, J., \& Jemal, A. Global cancer statistics, 2012. CA: a cancer journal for clinicians. $65(2), 87-108(2015)$

15. Petrylak, D. P., et al. Docetaxel and estramustine compared with mitoxantrone and prednisone for advanced refractory prostate cancer. The New England journal of medicine. 351 (15), 1513-1520 (2004).

16. Tannock, I. F., et al. Docetaxel plus prednisone or mitoxantrone plus prednisone for advanced prostate cancer. The New England journal of medicine. 351 (15), 1502-1512 (2004).

17. Sweeney, C. J., et al. Chemohormonal Therapy in Metastatic Hormone-Sensitive Prostate Cancer. The New England journal of medicine. 373 (8), 737-746 (2015).

18. Mahon, K. L., Henshall, S. M., Sutherland, R. L., \& Horvath, L. G. Pathways of chemotherapy resistance in castration-resistant prostate cancer. Endocrine-related cancer. 18 (4), R103-23 (2011). 
19. Follit, C. A., Brewer, F. K., Wise, J. G., \& Vogel, P. D. In silico identified targeted inhibitors of P-glycoprotein overcome multidrug resistance in human cancer cells in culture. Pharmacology research \& perspectives. 3 (5), e00170 (2015).

20. Ranganathan, S., Benetatos, C. A., Colarusso, P. J., Dexter, D. W., \& Hudes, G. R. Altered beta-tubulin isotype expression in paclitaxelresistant human prostate carcinoma cells. British journal of cancer. 77 (4), 562-566 (1998).

21. Martello, L. A., et al. Elevated levels of microtubule destabilizing factors in a Taxol-resistant/dependent A549 cell line with an alpha-tubulin mutation. Cancer research. 63 (6), 1207-1213 (2003).

22. Lee, A. J. X., et al. Chromosomal instability confers intrinsic multidrug resistance. Cancer research. 71 (5), 1858-1870 (2011).

23. Sansregret, L., \& Swanton, C. The Role of Aneuploidy in Cancer Evolution. Cold Spring Harbor perspectives in medicine. 7 (1) (2017).

24. Grasso, C. S., et al. The mutational landscape of lethal castration-resistant prostate cancer. Nature. 487 (7406), 239-243 (2012).

25. Taylor, B. S., et al. Integrative genomic profiling of human prostate cancer. Cancer cell. 18 (1), 11-22 (2010).

26. Gao, D., et al. Organoid cultures derived from patients with advanced prostate cancer. Cell. 159 (1), 176-187 (2014).

27. Drost, J. et al. Organoid culture systems for prostate epithelial and cancer tissue. Nature Protocols. 11 (2), $347-358$ (2016).

28. Domingo-Domenech, J. et al. Suppression of acquired docetaxel resistance in prostate cancer through depletion of notch- and hedgehogdependent tumor-initiating cells. Cancer cell. 22 (3), 373-388 (2012).

29. Vidal, S. J., et al. A targetable GATA2-IGF2 axis confers aggressiveness in lethal prostate cancer. Cancer cell. 27 (2), $223-239$ (2015).

30. Marín-Aguilera, M., et al. Identification of docetaxel resistance genes in castration-resistant prostate cancer. Molecular cancer therapeutics. 11 (2), 329-339 (2012).

31. Zhao, L., et al. Identification of candidate biomarkers of therapeutic response to docetaxel by proteomic profiling. Cancer research. 69 (19), 7696-7703 (2009).

32. Lin, H.-M., et al. Circulating microRNAs are associated with docetaxel chemotherapy outcome in castration-resistant prostate cancer. British journal of cancer. 110 (10), 2462-2471 (2014).

33. Puhr, M., et al. Epithelial-to-mesenchymal transition leads to docetaxel resistance in prostate cancer and is mediated by reduced expression of miR-200c and miR-205. The American journal of pathology. 181 (6), 2188-2201 (2012).

34. Rodriguez-Bravo, V., Carceles-Cordon, M., Hoshida, Y., Cordon-Cardo, C., Galsky, M. D., \& Domingo-Domenech, J. The role of GATA2 in lethal prostate cancer aggressiveness. Nature reviews. Urology. 14 (1), 38-48 (2017). 